\title{
Activation of Polymorphonuclear Leukocytes Reduces Their Adhesion to P-selectin and Causes Redistribution of Ligands for P-selectin on Their Surfaces
}

\author{
Diane E. Lorant, ${ }^{\star \S}$ Rodger P. McEver, ${ }^{\star *}$ Thomas M. McIntyre, ${ }^{\star \| 1}$ Kevin L. Moore, ${ }^{\star \star}$ Stephen M. Prescott, *\|1‡ \\ and Guy A. Zimmerman*\|l \\ * Nora Eccles Harrison Cardiovascular Research and Training Institute, ${ }^{\dagger}$ the Eccles Program in Human Molecular Biology and \\ Genetics, and the "Departments of Pediatrics, "Internal Medicine, and 'Biochemistry, of the University of Utah School of Medicine, Salt \\ Lake City, Utah 84112; and the **W.K. Warren Medical Research Institute, Departments of Medicine and Biochemistry, University of \\ Oklahoma Health Science Center, and the Cardiovascular Biology Research Program, Oklahoma Medical Research Foundation, \\ Oklahoma City, Oklahoma 73104
}

\begin{abstract}
In acute inflammatory responses, selectins mediate initial rolling of neutrophils (PMNs) along the endothelial surface. This is followed by tight adhesion that requires activationdependent up-regulation of CD11/CD18 integrins on PMNs. For emigration to occur, the initial bonds that are established at the endothelial surface must be disengaged. We show that activation of PMNs results in their detachment from P-selectin, a glycoprotein expressed at the surface of inflamed endothelium that mediates initial tethering of PMNs. Loosening of the bond occurs when PMNs are activated by platelet-activating factor, which is coexpressed with P-selectin, or by other signaling molecules. The time course of reduced adhesion to P-selectin, when compared to up-regulation of CD11/CD18 integrins, suggests that "bond trading" may occur as activated PMNs transmigrate in vivo. Activation of PMNs did not alter binding of fluid-phase $P$ selectin, indicating that the ligand(s) for P-selectin is not shed or internalized. Using microspheres coated with P-selectin, we found that ligands for P-selectin were randomly distributed over the surfaces of rounded, unactivated PMNs. An antibody against P-selectin glycoprotein ligand-1 (PSGL-1) completely inhibited binding of P-selectin-coated beads suggesting that $P$-selectin glycoprotein ligand-1 is the critical binding site in this assay. In contrast to the dispersed pattern on unactivated PMNs, the ligands for P-selectin were localized on the uropods of activated, polarized cells. Pretreating PMNs with cytochalasin D before activation prevented the change in cell shape, the redistribution of binding sites for P-selectin-coated beads, and the decrease in cellular adhesiveness for P-selectin. These experiments indicate that the distribution of ligands for P-selectin is influenced by cellular activation and by cytoskeletal interactions, and that redistribution of these ligands may influence adhesive interactions. Activation of PMNs may cause loosen-
\end{abstract}

Address correspondence to Diane E. Lorant, CVRTI, Building 500, University of Utah Medical Center, Salt Lake City, UT 84112. Phone:801-581-8183; FAX:801-581-3128.

Received for publication 18 October 1994 and accepted in revised form 31 March 1995.

J. Clin. Invest.

(C) The American Society for Clinical Investigation, Inc.

0021-9738/95/07/0171/12 \$2.00

Volume 96, July 1995, 171-182 ing or disengagement of bonds between P-selectin and its ligands, facilitating transendothelial migration. (J. Clin. Invest. 1995. 96:171-182.) Key words: endothelium • neutrophil • selectin - P-selectin glycoprotein ligand-1 - plateletactivating factor

\section{Introduction}

Adhesive interactions between PMNs, neutrophils, and endothelial cells regulate the targeting and transmigration of PMNs to foci of bacterial infection or tissue injury (1). Tethering of the two cells is critical. Molecules that establish or modify bonds between endothelial cells and PMNs are expressed on both cell types, and are diverse in structure and mechanism of expression (1-5). In an initial interaction, selectins expressed on the plasma membranes of stimulated endothelial cells bind to ligands on the PMN, causing them to "roll" on the endothelial surface $(2,6)$. Both P-selectin and E-selectin mediate rolling $(7-10)$. P-selectin is translocated to the plasma membrane from subcellular granules within minutes of stimulation of human endothelial cells with thrombin, histamine, or certain other agonists, whereas E-selectin expression is induced over hours by TNF $\alpha$, IL-1, or bacterial LPS and is under transcriptional regulation (reviewed in reference 1). L-selectin, which is present on the plasma membranes of PMNs and other leukocytes (1), also mediates rolling $(11,12,12 a)$.

After the initial rolling interaction, tight adhesion of PMNs occurs (3-5). This requires binding of CD11/CD18 integrins ( $\beta_{2}$ integrins) on the PMNs to intracellular adhesion molecules1 and 2 and, potentially, to unidentified counterligands on the endothelial surface (13). Cooperative tethering by selectins and $\beta_{2}$ integrins, resulting in tight adhesion, has been documented in vitro and in vivo $(8,14-16)$. Each of three CD11/CD18 heterodimers (CD11a/CD18, CD11b/CD18, CD11c/CD18) is constitutively present on the PMN plasma membrane. However, a qualitative alteration is required for the integrins to become competent to bind to counterreceptors on the endothelial cell. This is triggered by activation of the PMN, and is termed "functional upregulation" or "inside-out signaling" of the integrins $(1,17,18)$. Signaling factors that activate PMNs can be generated at extravascular sites and traditionally have been thought to operate in solution $(4,5,19)$. However, we showed that platelet-activating factor (PAF), a phospholipid that is rapidly synthesized and coexpressed with P-selectin by stimulated endothelial cells $(15,20)$, activates PMNs in a juxtacrine fashion while associated with the endothelial plasma membrane (15, 21, 22). Thus, both the initial tethering of the PMN by P- 
selectin and subsequent activation of CD11/CD18 integrins can be accomplished in a spatially localized fashion at the surface of the endothelial cell. IL-8, a second signaling molecule that is synthesized by stimulated endothelial cells, can also activate PMNs at, or near, their surfaces $(4,23-25)$. IL-8 is generated and acts in concert with E-selectin (1).

After initial tethering, activation, and adhesion strengthening, some PMNs develop polarized shape and migrate to extravascular sites (reviewed in references 4,5 ). This transmigration process involves the leukocyte CD11/CD18 integrins and a molecule associated with endothelial junctions, PECAM-1 (26). Sequential adhesion, movement, and subsequent use of additional tethering factors suggests that initial molecular bonds between the PMN and the endothelial cell are broken or modified. It is unknown how tethering of PMNs to the endothelial surface is loosened sufficiently for them to transmigrate without being swept away in flowing blood. However, the sequential steps outlined above suggest that the initial bonds must be modified in a regulated fashion. In the experiments reported here, we found that activation of PMNs reduces the tightness of their adhesion to surface P-selectin. This occurs within a time frame that would allow CD11/CD18 integrins to engage the endothelial surface before maximal loosening of the P-selectin component. In addition to causing reduced adhesion to surface Pselectin, activation of PMNs induces redistribution of ligands for P-selectin on their surfaces. Signaling molecules expressed by endothelial cells stimulate both loosening of the bonds to Pselectin and topographical redistribution of the ligands.

\section{Methods}

Materials. PAF was purchased from Avanti Polar Lipids, Inc., Birmingham, AL. L659,989 was generously supplied by John C. Chabala, Ph.D. of Merck, Sharp, and Dohme Research Laboratories, Rahway, NJ. Recombinant human TNF $\alpha$ was provided by R\&D Systems, Minneapolis, MN. 1,2-bis (0-aminophenoxyl) ethane- $N, N, N^{\prime}, N^{\prime}$-tetraacetic acid (BAPTA) ${ }^{1}$ was purchased from Calbiochem-Behring Corp., La Jolla, CA. Leukotriene $\mathrm{B}_{4}\left(\mathrm{LTB}_{4}\right), N$-Formyl-Met-Leu-Phe (f MLP), PMA, cytochalasin D, nocodazole, and colchicine were purchased from Sigma Chemical Co., St. Louis, MO. Glutaraldehyde was purchased from Electron Microscopy Sciences, Ft. Washington, PA. Recombinant human (ser-IL8) 72 was provided by Genzyme Corp., Cambridge, MA.

The anti-P-selectin mAbs, S12 and G1 (IgG1-K), were prepared and characterized as described $(27,28) . \Delta \mathrm{A} 4.4$ (IgG1), an anti-human $\mu$-chain mAb (29), was used as an isotype matched control and was kindly provided by John Bohnsack, University of Utah. PL1 and PL2 (IgG1- $\kappa$ ) are recently characterized antibodies against P-selectin glycoprotein ligand 1 (PSGL-1); PL1, but not PL2, blocks interaction of Pselectin with purified PSGL-1 and adhesion of myeloid leukocytes to P-selectin in a variety of assays (30). The anti-CD18 mAb, 60.3 (IgG2a) (31), was a gift from Patrick Beatty, University of Utah, and Kathy Cabrian of Bristol-Myers Squibb (Seattle, WA). The anti-Lselectin $\mathrm{mAb}$, Dreg 200.9 (IgG1), was provided by Boehringer Ingelheim Pharmaceuticals, Inc., Ridgefield, CT (32). Purified mouse nonimmune IgG was from Cappel-Organon Teknika, Durham, NC.

1. Abbreviations used in this paper: BAPTA, 1,2-bis (0-aminophenoxyl) ethane- $N, N, N^{\prime}, N^{\prime}$,-tetraacetic acid; $\left[\mathrm{Ca}^{2+}\right] \mathrm{i}$, intracellular calcium; CHO, chinese hamster ovary; f MLP, N-formyl-Met-Leu-Phe; HBSS / A, HBSS containing $0.5 \%$ HSA; LAI, leukocyte adhesion inhibitor; $\mathrm{LTB}_{4}$, leukotriene $\mathrm{B}_{4} ; \mathrm{mPS}$, transmembrane form of P-selectin; PAF, platelet-activating factor; PSGL-1, P-selectin glycoprotein ligand-1.
FITC-conjugated anti-mouse IgG was from Sigma Chemical Co., St. Louis, MO.

Cells. Primary, confluent, human umbilical vein endothelial cell monolayers were prepared as described $(15,21,33)$. Chinese hamster ovary (CHO) cells stably transfected with a cDNA for P-selectin (34) were maintained and characterized as described (22). In subsequent text they are referred to as "transfected CHO cells" or "P-selectin transfectants." Adhesion of PMNs to these transfected CHO cells does not require cellular activation, is $\mathrm{Ca}^{2+}$-dependent, is blocked by monoclonal antibodies against the lectin domain of P-selectin, is competed by nanomolar concentrations of the transmembrane form of P-selectin (mPS) (see below), and is inhibited by treatment of the PMNs with the $O$-sialylglycoprotease from Pasturella haemolytica A1 (reference 22, and unpublished experiments).

HL60 promyelocytic leukemia cells were obtained from the American Type Culture Collection, Rockville, MD, and were maintained in medium RPMI-1640 supplemented with $20 \%$ heat-inactivated FBS. These cells were used after $15-20$ passages.

Whole blood was obtained from healthy adult volunteers or from a patient with complete absence of surface expression of CD11/CD18 glycoproteins in both the resting and stimulated state $(15,35)$. PMN isolation and labeling with ${ }^{111}$ In were performed as described $(21,33)$. Quantitative adhesion assays were done with radiolabeled PMNs; otherwise, unlabeled cells were used. In either case, incubations were done with PMNs suspended in Hanks Balanced Salt Solution containing 0.5\% human serum albumin $(\mathrm{HBSS} / \mathrm{A})\left(5.5 \times 10^{6} \mathrm{cells} / \mathrm{ml}\right)$ except where noted.

Selectins. mPS was purified from human platelet lysates as previously described (36). For adhesion assays, $16-\mathrm{mm}$ Nunclon ${ }^{\circledR}$ plastic wells (Nunc, Inc., Naperville, IL) were coated with $0.3 \mathrm{ml}$ of $2 \mu \mathrm{g} / \mathrm{ml}$ $\mathrm{mPS}$ in HBSS overnight at $4^{\circ} \mathrm{C}$. Nonspecific binding was blocked by incubating the wells in $10 \mathrm{mg} / \mathrm{ml} \mathrm{HSA}$ for $2 \mathrm{~h}$ and washing thrice with $0.1 \%$ Tween-20. The wells were then washed once with HBSS and stored at $4^{\circ} \mathrm{C}$ until ready for use. In some experiments mPS was incorporated into planar membranes as described previously (22).

PMN adhesion assays. Adhesion of "11'In-labeled PMNs to transfected CHO cells, to immobilized P-selectin, to P-selectin incorporated into model membranes, and to stimulated endothelial cells was performed as described $(15,22,33)$. To measure PMN adhesion to Pselectin independent of the CD11/CD18 integrins, we used the following strategies: (a) PMN were incubated with $60.3(10 \mu \mathrm{g} / \mathrm{ml})$, a blocking $\mathrm{mAb}$ to $\mathrm{CD} 18$, at $37^{\circ} \mathrm{C}$ for $10 \mathrm{~min}$ before the assay (15). (b) Assays were performed on an orbital shaker (Bellco Biotechnology, Vineland, NJ) at $64 \mathrm{rpm}$ (37). This approach was based on the observations that shear inhibits CD11/CD18 integrin-mediated adhesion of leukocytes $(2,3,7)$, and orbital shakers impose shear stresses estimated to be in the range of those measured in postcapillary venules, although the orbital shear forces cannot be precisely quantified (37a). (c) PMNs were suspended in a buffer without magnesium $(38,39)$. This was prepared using calcium- and magnesium-free HBSS (BioWhittaker, Inc., Walkersville, MD) to which $5 \mathrm{mM} \mathrm{CaCl}_{2}$ was added. (d) Assays were performed with PMNs from a patient with leukocyte adhesion deficiency type $1(15,35)$. Each of these approaches prevented the adhesion of PAF- or $\mathrm{ALP}$-stimulated PMNs to wild-type CHO cells, which occurs by a CD11/CD18-dependent mechanism (reference 22 and unpublished experiments).

Flow cytometry. Modifications of our previously described methods (22) were used to analyze binding sites for P-selectin on PMNs by flow cytometry. PMNs were stimulated at $37^{\circ} \mathrm{C}$ and then kept at $4^{\circ} \mathrm{C}$ for flow cytometry. To measure binding of $\mathrm{mPS}$ to its ligand(s) on PMNs, the cells $\left(10^{6} / \mathrm{ml}\right)$ were suspended in $200 \mu \mathrm{l}$ of HBSS $/ \mathrm{A} / 0.1 \%$ azide containing $\mathrm{mPS}(10 \mu \mathrm{g} / \mathrm{ml})$. After $30 \mathrm{~min}$ at $4^{\circ} \mathrm{C}$, PMNs were washed in $0.5 \mathrm{ml} \mathrm{HBSS} / \mathrm{A} / 0.1 \%$ azide and then resuspended in $200 \mu \mathrm{l}$ of $\mathrm{mAb} \mathrm{S12}(10 \mu \mathrm{g} / \mathrm{ml}$ in HBSS/A/0.1\% azide), a nonblocking antibody against P-selectin $(27,28)$. The cells were kept on ice for an additional $30 \mathrm{~min}$ and then washed and resuspended in a 1:100 dilution of FITCconjugated goat anti-mouse IgG. After $30 \mathrm{~min}$, PMNs were washed, resuspended in $1 \%$ paraformaldehyde, and fluorescence was measured 


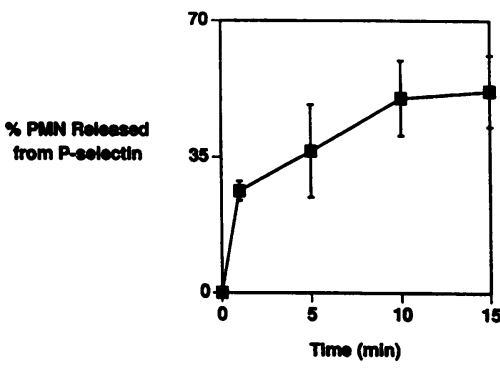

lectin on their surfaces. The PMNs were allowed to adhere for $10 \mathrm{~min}$ at $37^{\circ} \mathrm{C}$ and the wells were gently washed once. PAF $\left(10^{-7} \mathrm{M}\right)$ or control buffer was added, the cells were incubated at $37^{\circ} \mathrm{C}$ in $5 \% \mathrm{CO}_{2}$, 95\% air, and the number of PMNs that remained adherent was determined after the times shown. The points represent the mean \pm range of two independent experiments performed in duplicate. A third experiment done under slightly different conditions gave similar results.

using a FACScan ${ }^{\oplus}$ flow cytometer (Becton Dickinson and Co., Mountain View, CA) (22). Incubations were also done in the absence of $\mathrm{Ca}^{2+}$ (by suspending the cells in divalent cation-free HBSS containing $0.5 \%$ albumin and $5 \mathrm{mM}$ EDTA) to determine nonspecific binding of $\mathrm{mPS}$ to the PMNs $(28,40)$. mAb $\triangle \mathrm{A} 4.4$ was used as an isotype matched negative control (29). PMNs were suspended in $200 \mu \mathrm{l}$ of 10 $\mu \mathrm{g} / \mathrm{ml} \Delta \mathrm{A} 4.4$ in HBSS $/ \mathrm{A} / 0.1 \%$ azide for $30 \mathrm{~min}$. The PMNs were then washed and resuspended in a 1:100 dilution of FITC-conjugated goat anti-mouse IgG. After 30 min they were washed again and fixed in $1 \%$ paraformaldehyde.

For measurement of L-selectin expression on the PMN surface, PMNs were suspended in HBSS $/ \mathrm{A} / 0.1 \%$ azide containing $10 \mu \mathrm{g} / \mathrm{ml}$ Dreg 200.9, an anti-L-selectin $\mathrm{mAb}$, and kept on ice for $45 \mathrm{~min}$. PMNs were then washed in cold HBSS/A/0.1\% azide, resuspended in a 1:100 dilution of FITC-conjugated goat anti-mouse IgG, and incubated on ice for $30 \mathrm{~min}$. After washing again in cold HBSS/A/0.1\% azide, the PMNs were resuspended in $1 \%$ paraformaldehyde and fluorescence was measured. Nonspecific binding was measured by first suspending the PMNs in $10 \mu \mathrm{g} / \mathrm{ml}$ of control mouse IgG, followed by FITC conjugated anti-mouse IgG.

Intracellular calcium chelation. Intracellular calcium was chelated by incubating PMNs with $10^{-6} \mathrm{M}$ BAPTA at $37^{\circ} \mathrm{C}$ for $30 \mathrm{~min}$ in HBSS/ $A$ free of $\mathrm{Ca}^{2+}$ and $\mathrm{Mg}^{2+}$. PMNs were subsequently suspended in HBSS/A with $1.3 \mathrm{mM} \mathrm{Ca}^{2+}$. To confirm that this treatment prevented an increase in intracellular $\mathrm{Ca}^{2+}\left(\left[\mathrm{Ca}^{2+}\right]_{\mathrm{i}}\right)$ in stimulated PMNs, we measured $\left[\mathrm{Ca}^{2+}\right]_{\mathrm{i}}$ transients as previously described (22).

Assessment of distribution of ligands for P-selectin on PMNs using microspheres. The distribution of binding sites for P-selectin on the PMN surface was assessed by incubating resting and activated PMNs with latex beads coated with P-selectin. Carboxyl latex fluorospheres ( $1 \mu \mathrm{m}$ diameter, Molecular Probes, Inc., Eugene, OR) were coated with $\mathrm{mPS}$ by incubating $50 \mu \mathrm{l}$ of beads ( $2 \%$ beads by weight, as supplied by the manufacturer) in $150 \mu \mathrm{l}$ PBS containing mPS (10-20 $\mu \mathrm{g})$ for $1 \mathrm{~h}$ at $37^{\circ} \mathrm{C}$. The beads were then blocked by incubating them in PBS containing $10 \mathrm{mg} / \mathrm{ml}$ human albumin for an additional $1 \mathrm{~h}$ at $37^{\circ} \mathrm{C}$. They were then centrifuged at $1,350 \mathrm{rpm}$ for $5 \mathrm{~min}$ at $20^{\circ} \mathrm{C}$ and resuspended in $0.2 \mathrm{ml}$ of PBS. PMNs at $5.5 \times 10^{6} \mathrm{cells} / \mathrm{ml}$ were incubated with control buffer or with an agonist that induced activation; $5 \mu \mathrm{l}$ of P-selectincoated beads were then combined with $45 \mu \mathrm{l}$ of PMNs (ratio of beads to cells $=183: 1$ ) for $15 \mathrm{~min}$ at $37^{\circ} \mathrm{C}$ under unstirred conditions. PMNs were fixed in $1 \%$ glutaraldehyde for $1 \mathrm{~h}$ at $4^{\circ} \mathrm{C}$. PMNs with attached beads were then centrifuged at $1,350 \mathrm{rpm}$ and resuspended in $25 \mu$ l PBS. Inspection of the PMN suspension by light microscopy demonstrated that, in the process of centrifugation, some beads were lost from the PMN surface but the distribution was unchanged. In some experiments the distribution of the P-selectin-coated beads on the PMN surface was examined and photographed with Normarski interference contrast optics using light microscope (Axioplan; Carl Zeiss, Inc.,

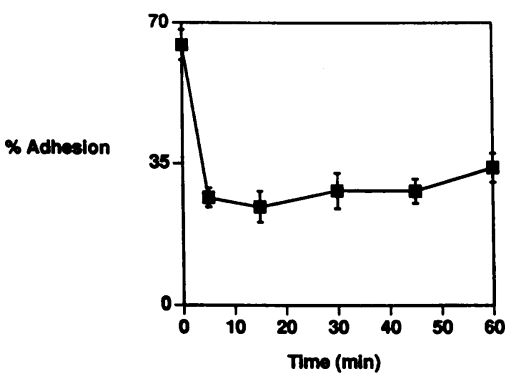

Figure 2. Decreased adhesion of activated PMNs to P-selectin at cell surfaces is rapid and sustained. ${ }^{111}$ In-labeled PMNs were suspended in buffer free of $\mathrm{Mg}^{2+}$, divided into aliquots, and $\operatorname{PAF}\left(10^{-7} \mathrm{M}\right)$ was added to each aliquot. After incubation for the times shown, PMNs

were layered over transfected $\mathrm{CHO}$ cells and adhesion was measured after $10 \mathrm{~min}$ at $37^{\circ} \mathrm{C}$. The points indicate the means and ranges of values in duplicate experiments.

Thornwood, NY). The specificity of bead binding to PMNs was measured by incubating an aliquot of beads for $30 \mathrm{~min}$ at $37^{\circ} \mathrm{C}$ with $50 \mu \mathrm{g} /$ $\mathrm{ml}$ of the $\mathrm{F}\left(\mathrm{ab}^{\prime}\right)_{2}$ fragment of the blocking anti-P-selectin mAb, G1, or the $\mathrm{F}\left(\mathrm{ab}^{\prime}\right)_{2}$ fragment of the nonblocking mAb, S12. In additional studies of specificity, binding of P-selectin-coated beads to PMNs was done in $\mathrm{Ca}^{2+}$-free buffer. In some experiments PMNs were incubated for $10 \mathrm{~min}$ at $37^{\circ} \mathrm{C}$ with $27 \mu \mathrm{g} / \mathrm{ml}$ of the blocking mAb to PSGL-1, PL1, or the nonblocking mAb, PL2 (30), before the bead binding assay.

In certain experiments the protocol outlined above was varied by: (a) fixation of PMNs before, rather than after, incubation with beads, (b) sequential stimulation of PMNs with $\mathrm{fMLP}$ as described by Hughes et al. (41) to induce pronounced uropod formation. The distribution of beads on resting and stimulated PMNs described in Results did not differ in experiments with these variations, although in some cases there were differences in the total number of beads bound per cell.

Statistics. Analysis of variance was used to compare the means of several groups and the statistical significance between groups was assessed using a paired Student's $t$ test.

\section{Results}

Activation releases $P M N$ s tethered by P-selectin. In initial experiments to determine if activation of PMNs alters their adhesion to P-selectin, PAF was chosen as the activating signal because it is coexpressed and acts in concert with P-selectin on the surfaces of stimulated endothelial cells $(15,22)$. Since PAF is also a potent agonist for functional upregulation of CD11/ CD18 integrins $(33,42)$, we reasoned that alterations in adhesion of PMNs to P-selectin induced by activation might be masked by increased adhesiveness mediated by the integrins. Therefore, we suspended PMNs in a $\mathrm{Mg}^{2+}$-free buffer to block the integrin-mediated adhesiveness $(38,39)$ and then incubated the PMNs with transfected CHO cells that express P-selectin. The PMNs adhered avidly, as in previous experiments (22). PAF was then added to activate the PMNs. We found that, within $1 \mathrm{~min}$, the tightness of binding of the PMNs was reduced, so that they were released from the monolayer (Fig. 1). By 5-10 min release was maximal. These results indicated that activation of PMNs subsequent to tethering to P-selectin reduces the adhesive interaction.

Characterization of decreased adhesion of activated PMNs to P-selectin. Activation of PMNs frequently caused dramatic reduction in their adhesion to P-selectin transfectants (Figs. 2 and 3, and data not shown). In multiple studies in which PMNs were activated either before or after adhesion to transfected CHO cells, PAF reduced their adhesion to P-selectin by a mean of $48 \%$ compared to the adhesion of unactivated PMNs ( $P$ 


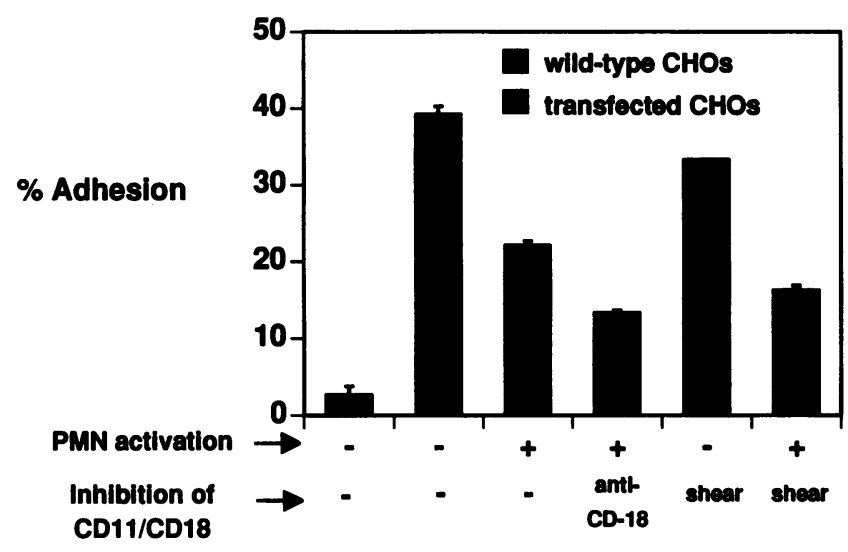

Figure 3. Blocking CD11/CD18 integrins magnifies the activation-dependent decreased adhesion of PMNs to P-selectin. PMNs were treated with buffer or the anti-CD18 $\mathrm{mAb} 60.3$ for $10 \mathrm{~min}$ at $37^{\circ} \mathrm{C}$, and an aliquot of PMNs from each group was activated with $2 \times 10^{-7} \mathrm{M}$ PAF for $5 \mathrm{~min}$ at $37^{\circ} \mathrm{C}$. PMNs were then layered onto $\mathrm{CHO}$ cells that were kept static and adhesion was measured after $5 \mathrm{~min}$ at room temperature. In parallel, resting or activated PMNs were incubated for $5 \mathrm{~min}$ on transfected $\mathrm{CHO}$ cells that were subjected to shear on an orbital shaker. The bars indicate the mean of duplicate determinations in a single experiment and the error bars the range.

$=0.0001)$. The altered adhesiveness of activated PMNs for Pselectin was blocked by a specific competitive antagonist of the PAF receptor, L659,989 $(15,21)$. When undifferentiated HL60 cells, a myeloid precursor that expresses a high-affinity ligand for P-selectin $(30,43,44)$ but not the signal transducing receptor for PAF (45), were pretreated with PAF, their adhesion to P-selectin transfectants was not reduced compared to HL60 cells pretreated with buffer alone. This further suggests that reduced adhesion of mature PMNs to P-selectin resulting from treatment with PAF is dependent on the signal-transducing receptor and cellular activation. The effect of PAF was concentration-dependent, with a threshold at or below $0.1 \mathrm{nM}$ and maximal inhibition at $\sim 1.0 \mathrm{nM}$, with no greater reduction in adhesion at higher concentrations. Decreased adhesion to P-selectin always occurred within minutes of addition of PAF, although there was some variation in the time required to achieve the maximal effect (Figs. 1 and 2, and data not shown). The effect persisted for at least $60 \mathrm{~min}$ (Figs. 1 and 2). This time course was the same if PAF was continuously present, or if PMNs were stimulated for $5 \mathrm{~min}$ and then resuspended in buffer without PAF for the remaining $55 \mathrm{~min}$ (not shown). In contrast to the time course shown in Fig. 2, unactivated PMNs remained tethered to transfected $\mathrm{CHO}$ cells for at least $45 \mathrm{~min}$. (not shown). When PMNs were released from adhesion to P-selectin by activation as in Fig. 1 and transferred to new monolayers of transfected CHO cells, decreased adhesion was also seen.

We found that, in addition to PAF, f MLP, IL-8, and LTB $_{4}$ reduced the adhesion of PMNs to transfected $\mathrm{CHO}$ cells (Table I). In individual experiments, treatment of PMNs with TNF $\alpha$, PMA, or calcium ionophore A23187 had a similar effect (not shown). This demonstrated that the altered adhesion to surface $\mathrm{P}$-selectin is not restricted to a single agonist, and further indicates that this is an activation-dependent response. Treatment of PMNs with PAF or IMLP reduced their adhesion to Pselectin immobilized on plastic and to P-selectin incorporated into model membranes (22), as well as to P-selectin expressed
Table I. Activation of PMNs by Signaling Molecules Reduces Adhesion to P-selectin

\begin{tabular}{lccc}
\hline \multicolumn{1}{c}{ Agonist } & Concentration & Time & Inhibition \\
\hline & & $\min$ & $\%$ \\
PAF & $10^{-7} \mathrm{M}$ & 5 & 56 \\
LTB $_{4}$ & $10^{-7} \mathrm{M}$ & 5 & 58 \\
$\mathrm{fMLP}_{\text {IL-8 (ser-IL8 }}$ ) & $10^{-7} \mathrm{M}$ & 5 & 50 \\
& $5 \times 10^{-9} \mathrm{M}$ & 5 & 52 \\
\hline
\end{tabular}

CD11/CD18-mediated adhesion was blocked by deleting $\mathrm{Mg}^{2+}$ from the buffer. PMNs were pretreated with agonists for $5 \mathrm{~min}$, layered over transfected CHO cells expressing P-selectin, and incubated for $10 \mathrm{~min}$. The percent inhibition was calculated by comparing adhesion of PMNs treated with activating agonists to adhesion of PMNs treated with control buffer. The values indicate the means of duplicate determinations.

by transfected cells. In an experiment to determine if the mechanism of decreased adhesion involved degradation of P-selectin, we incubated replicate wells containing immobilized P-selectin with buffer alone, resting PMNs, or PMNs that were activated with $\mathrm{f} \mathrm{MLP}\left(10^{-6} \mathrm{M}\right)$. After $5 \mathrm{~min}$ at $37^{\circ} \mathrm{C}$, the adherent PMNs were eluted with EDTA and unactivated radiolabeled PMNs were added to the wells. There was no difference in adhesion of labeled PMNs to immobilized P-selectin that had been preincubated with $f$ MLP-stimulated PMNs compared to adhesion to $P$-selectin in control wells. In a second experiment, we activated PMNs in suspension and then resuspended them in fresh buffer. The degree of inhibition of binding to transfected $\mathrm{CHO}$ cells was the same for activated PMNs in the original buffer and the fresh buffer. These experiments suggest that the mechanism of decreased binding of activated PMNs to P-selectin is not by release of factors by activated PMNs.

We further explored the ability of CD11/CD18 integrins to mask decreased adhesion of activated PMNs to P-selectin. While partial inhibition of adhesion to P-selectin could be detected in some experiments when PMNs were activated with the CD11/CD18 integrin adhesive mechanism intact, it was most consistent and of greatest magnitude when these integrins were blocked (Fig. 3). Treatment of PMNs with mAb 60.3 or suspension of the leukocytes in $\mathrm{Mg}^{2+}$-free buffer were equally effective in achieving inhibition and magnifying the decreased adhesion of activated PMNs to P-selectin. The degree of decreased adhesion was comparable to that observed when CD11/ CD18-deficient PMNs from a subject with leukocyte adhesion deficiency type I (13) were studied (not shown). Use of rotary shear to inhibit CD11/CD18 integrins $(13,37)$ also magnified the decreased adhesion resulting from PMN activation (Fig. 3).

To directly determine if decreased adhesion of activated PMNs to P-selectin expressed by transfected cells is relevant to adhesive interactions with endothelial cells, we treated PMNs with an activating signal and examined their adhesion to endothelial cells stimulated with $2 \mathrm{U} / \mathrm{ml}$ thrombin (33), which induces surface expression of P-selectin (15). We previously found that pretreatment of PMNs with PAF dramatically reduced their adhesion to thrombin-stimulated endothelial monolayers (33). However, PAF is coexpressed with P-selectin under these conditions, and a component of this decreased adhesion is due to homologous desensitization of the PAF receptor (21, 33). Therefore, we used $\mathrm{f} \mathrm{MLP,} \mathrm{which} \mathrm{is} \mathrm{recognized} \mathrm{by} \mathrm{a} \mathrm{differ-}$ 


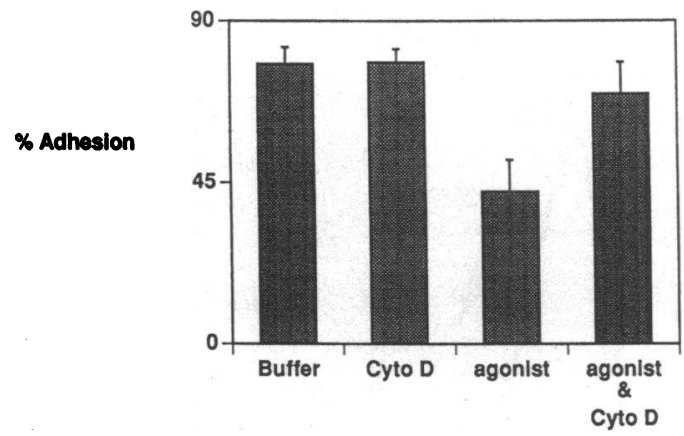

Figure 4. Cytochalasin D prevents the activation-dependent decreased adhesion of PMNs to P-selectin. This figure represents the results from three separate experiments in which cytochalasin $D$ prevented decreased binding of activated PMNs to P-selectin. Adhesion mediated by CD11/ CD18 integrins was blocked by either incubating PMNs with mAb 60.3 or by suspending PMNs in $\mathrm{Mg}^{2+}$-free buffer, which are equivalent in their ability to inhibit this interaction (see text). PMNs were pretreated with cytochalasin D $\left(2 \times 10^{-6} \mathrm{M}\right)$ or with vehicle alone (DMSO, $0.1 \%$ ) for $10 \mathrm{~min}$ at $37^{\circ} \mathrm{C}$. The PMNs were then activated with PAF (one experiment) or with f MLP (two experiments). After activation, the PMNs were layered over transfected CHO cells and adhesion was measured. The bars indicate the mean values and the error bars the standard deviation. The bar legends indicate the following conditions: (Buffer) no cytochalasin D, no activating agonist; (Cyto D) cytochalasin $\mathrm{D}$ included, no activating agonist; (agonist) no cytochalasin D, activating agonist included; (agonist and Cyto D) cytochalasin D and activating agonist included. In four additional experiments, cytochalasin D also prevented the decreased adhesion of activated PMNs to P-selectin (see Fig. $6 b$ and data not shown). In all seven experiments, there was no statistical difference in the means between the groups treated with buffer, cytochalasin $\mathrm{D}$, or cytochalasin $\mathrm{D}$ with an agonist $(P=0.42)$. There was a statistically significant difference between the group treated with an agonist and those groups treated with buffer, cytochalasin D, and cytochalasin D with an agonist ( $P=0.0001$ for each comparison).

ent receptor, as the activating signal. In two experiments, pretreatment of PMNs with $\mathrm{fMLP}\left(10^{-7} \mathrm{M}\right.$ for $\left.5 \mathrm{~min}\right)$ in $\mathrm{Mg}^{2+}$. free buffer reduced their adhesion to endothelial cells stimulated with thrombin by a mean of $66 \%$ (range $31-100 \%$ ) when compared to the adhesion of unactivated PMNs. This result is consistent with the findings in experiments using $\mathrm{CHO}$ cells expressing P-selectin (Figs. 1-3; Table I).

Decreased adhesion of activated PMNs to P-selectin is prevented by cytochalasin $D$. Because cytoskeletal alterations modify a variety of molecular interactions at the PMN surface, we asked if actin polymerization is required for the decreased adhesion of activated PMNs to P-selectin. We chose cytochalasin $D$ to inhibit actin assembly because of its specificity and potency $(46,47)$. PMNs were pretreated with cytochalasin D and then activated. Cytochalasin D prevented the decreased adhesion to P-selectin transfectants induced by cellular activation (Figs. 4 and $6 b$ ). Pretreatment of PMNs with cytochalasin $D$ alone (i.e., no agonist for activation) did not alter their adhesion to P-selectin (Fig. 4). To examine the specificity of adhesion of PMNs pretreated with cytochalasin D under the conditions shown in Fig. 4, we incubated the cells with the anti-Pselectin mAb, G1. mAb G1 completely inhibited adhesion to P-selectin transfectants, whereas control antibodies did not (not shown). This result indicates that treatment of PMNs with cytochalasin D did not induce an alternative adhesive mechanism and that its effect involves alterations in ligands for P-selectin.

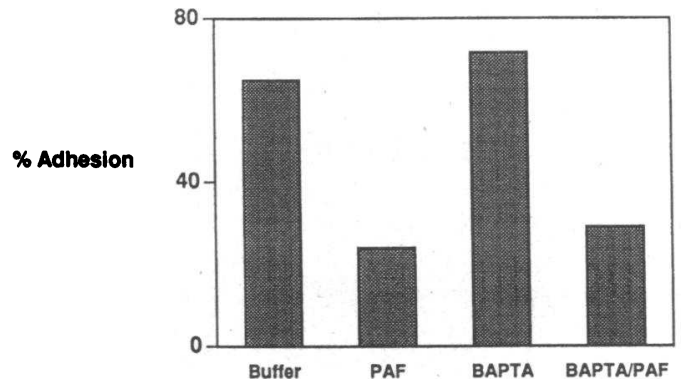

Figure 5. Decreased adhesion of activated PMNs to cell surface Pselectin is not blocked by buffering intracellular $\mathrm{Ca}^{2+}$. PMNs were preincubated with $10 \mu \mathrm{M}$ BAPTA at $37^{\circ} \mathrm{C}$ for $30 \mathrm{~min}$. They were then incubated with mAb 60.3 to block CD18 integrins, and activated with PAF $\left(10^{-7} \mathrm{M}\right)$. PAF-treated or control PMNs were layered over transfected CHO cells and adhesion was measured after a 10-min incubation. The bars indicate single points from one experiment. The results in five additional experiments were similar.

In contrast to cytochalasin $\mathrm{D}$, nocodazole and colchicine, agents that disrupt microtubules, did not prevent altered adhesion to P-selectin.

Decreased adhesion of activated PMNs to P-selectin is independent of an increase in intracellular $\mathrm{Ca}^{2+} .\left[\mathrm{Ca}^{2+}\right]_{\mathrm{i}}$ transient is required for PMNs to release from immobilized matrix proteins (48), suggesting that this signaling event may be a requisite for modification of bonds during cell migration (49). However, when we chelated $\left[\mathrm{Ca}^{2+}\right]_{\mathrm{i}}$ with BAPTA, the reduction in adhesion of activated PMNs to transfected CHO cells was not different from that of activated control PMNs (Fig. 5). This result is consistent with the experiments indicating that cytoskeletal rearrangement is required for reduced adhesion to P-selectin (Fig. 4), since increased intracellular calcium is not necessary for actin polymerization (50). BAPTA blocked an increase in $\left[\mathrm{Ca}^{2+}\right]_{\mathrm{i}}$ in stimulated PMNs measured by parallel spectrofluorimetric assays (not shown), documenting its efficacy.

Altered adhesion of activated PMNs to P-selectin is dissociated from shedding of L-selectin. When PMNs are activated, Lselectin is shed from their surfaces by proteolytic cleavage (32, 51,52 ). Earlier, it was reported that L-selectin may be a ligand for P-selectin (53). These two observations suggested that decreased adhesion of activated PMNs to cells expressing P-selectin may be due to loss of L-selectin from the PMN surface. To examine this issue, we used flow cytometry to detect L-selectin shedding from PMNs activated in the presence or absence of cytochalasin D (see above), and compared this change in surface phenotype to their adhesion to P-selectin transfectants. Treatment of PMNs with PAF or f MLP induced shedding of L-selectin, as expected (Fig. 6). In PMNs pretreated with cytochalasin D and then activated with PAF or f MLP, L-selectin was shed to the same extent as in control PMNs (Fig. $6 a$ ). In parallel incubations, the inhibition of adhesion of activated PMNs to transfected CHO cells was prevented by cytochalasin treatment (Fig. $6 b$ ), as in earlier experiments (Fig. 4), even though $\sim 90 \%$ of the surface L-selectin had been shed (Fig. 6 $a)$. These experiments indicate that shedding of L-selectin does not account for decreased adhesion of activated PMNs to Pselectin.

PMN activation does not alter the apparent number of binding sites for P-selectin in solution. We previously reported that 


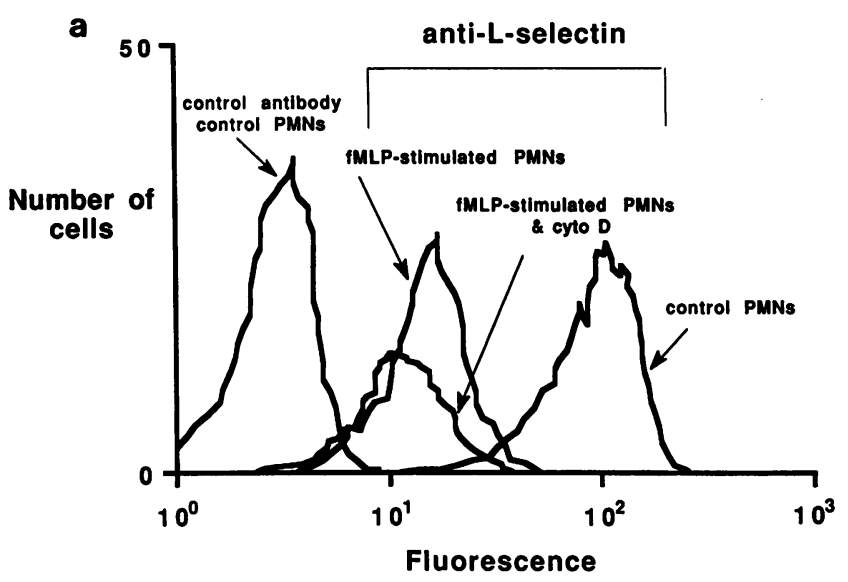

b

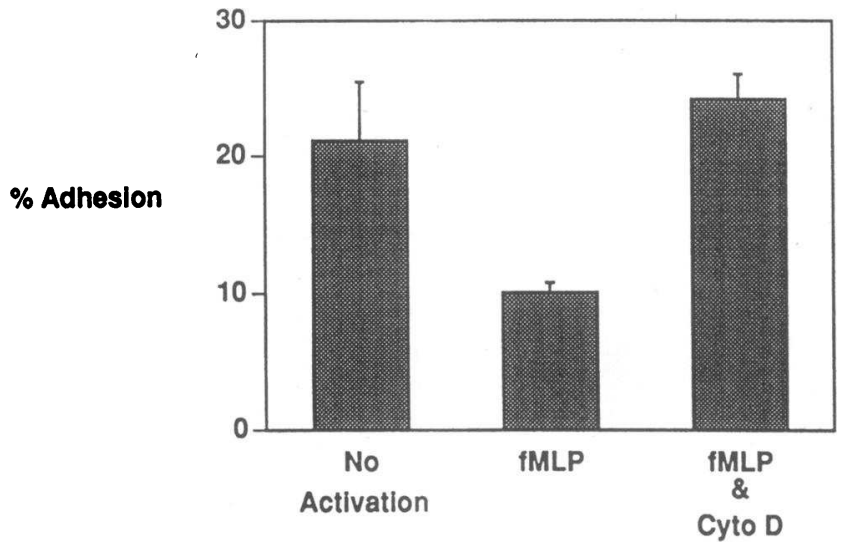

Figure 6. Shedding of L-selectin does not account for decreased adhesion of activated PMNs to P-selectin at cell surfaces. (a) PMNs $\left(10^{6} /\right.$ $\mathrm{ml})$ were treated with cytochalasin D $\left(2 \times 10^{-6} \mathrm{M}\right)$ or DMSO $(0.1 \%)$ as in Fig. 4, and CD11/CD18-mediated adhesion was blocked with $\mathrm{mAb} 60.3$. The cells were then activated with $\mathrm{f} \operatorname{MLP}\left(10^{-6} \mathrm{M}\right)$, or treated with control buffer, for $5 \mathrm{~min}$ at $37^{\circ} \mathrm{C}$. The PMNs were immediately put on ice and washed with cold HBSS/A containing $0.1 \%$ azide. After pelleting, they were resuspended in buffer containing a monoclonal antibody to L-selectin (Dreg 200.9, $10 \mu \mathrm{g} / \mathrm{ml}$ ) or nonimmune murine IgG $(10 \mu \mathrm{g} / \mathrm{ml})$ and were kept on ice for $45 \mathrm{~min}$. The PMNs were then washed in cold HBSS/A containing $0.1 \%$ azide, resuspended in buffer containing FITC-conjugated goat anti-mouse IgG, and kept on ice for an additional $30 \mathrm{~min}$. After washing again in HBSS/A with $0.1 \%$ azide, the PMNs were fixed in $1 \%$ paraformaldehyde. Fluorescence was then measured as described (22). A second experiment done under the same conditions yielded a similar result. (b) In parallel, PMNs were pretreated with cytochalasin $D$ or vehicle, layered over transfected CHO cells expressing P-selectin, treated with f MLP $\left(10^{-6} \mathrm{M}\right)$ or control buffer, and adhesion was measured after a 5-min incubation at $37^{\circ} \mathrm{C}$. Activation of control PMNs (no cytochalasin D) with $\mathrm{f} \mathrm{MLP} \mathrm{reduced}$ their adhesion to $\mathrm{CHO}$ cells expressing P-selectin, as expected; this decreased adhesion was completely prevented by pretreatment of PMNs with cytochalasin $\mathrm{D}$.

ligand density and apparent affinity for P-selectin were not altered when PMNs were stimulated with PMA, based on experiments using equilibrium binding of radiolabeled P-selectin (36). This suggested that the binding sites for P-selectin on the PMN surface are not shed or internalized in response to cellular activation, and is consistent with the experiments examining

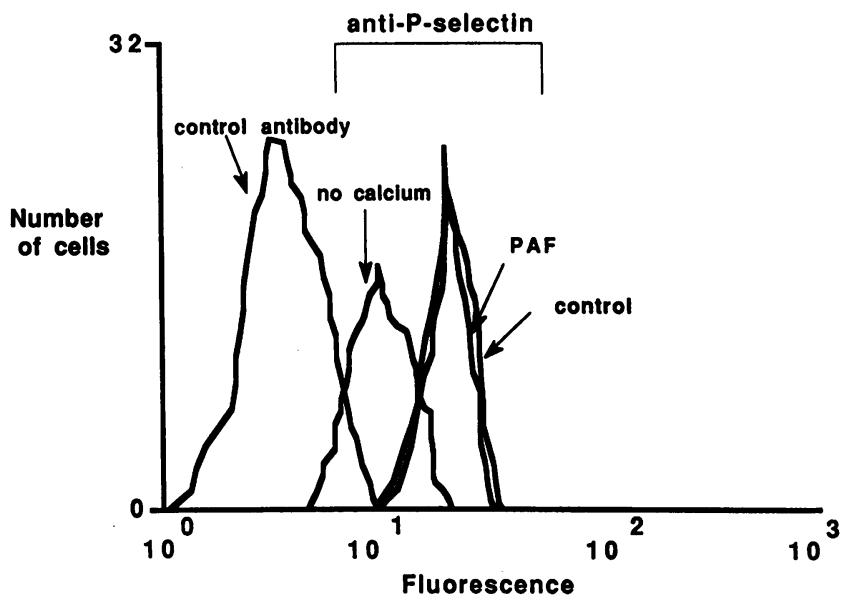

Figure 7. Activation of PMNs does not reduce binding sites for Pselectin when measured by flow cytometry. PMNs were suspended in $\mathrm{Mg}^{2+}$-free buffer to prevent CD11/CD18-dependent aggregation upon activation. They were then treated with control buffer, or with $10^{-7} \mathrm{M}$ PAF for 10 min, and the surface binding of mPS was measured by flow cytometry using an anti-P-selectin $\mathrm{mAb}$. In parallel, association of $\mathrm{P}$ selectin with PMNs was measured in $\mathrm{Ca}^{2+}$-free buffer (see Methods) to determine nonspecific binding $(36,65)$. We found similar results in two additional experiments done under slightly different conditions.

the role of L-selectin shedding (above). To examine this issue in a different way, binding of $\mathrm{mPS}$ presented in solution to control or activated PMNs was examined by flow cytometry using murine mAb S12 to detect surface P-selectin followed by a fluorescently labeled goat anti-mouse mAb. We found that P-selectin bound equivalently to control PMNs and to PMNs activated with $10^{-7} \mathrm{M}$ PAF (Fig. 7). In parallel incubations, activation of PMNs with PAF reduced their adhesion to transfected CHO cells (not shown), as expected from earlier experiments. This result again suggested that the number of binding sites for P-selectin on the PMN is not reduced by cellular activation, and that the decreased adhesion of activated PMNs to surface-bound P-selectin results from a qualitative change in ligands that recognize $\mathrm{P}$-selectin or a redistribution of these ligands on the plasma membranes of activated PMNs.

Decreased adhesion of PMNs to P-selectin is correlated with redistribution of ligands on activated cells. To examine the distribution of the ligand( $s$ ) for P-selectin on PMNs, latex beads coated with P-selectin were incubated with PMNs and the distribution of the microspheres was examined by light microscopy and with Normarski interference contrast optics. In initial studies we found that P-selectin-coated microspheres avidly bound to unactivated PMNs. This binding was not inhibited by mAb 60.3 or by removal of $\mathrm{Mg}^{2+}$ from the medium. Furthermore, beads coated with albumin alone, which was used to block P-selectin-coated beads ( see Methods), did not bind to PMNs under the conditions of these experiments. These findings indicated that interaction of the microspheres coated with Pselectin was not due to recognition of albumin on the bead surface by CD11b/CD18 on the PMN $(41,54)$. Binding of Pselectin-coated beads to unactivated PMNs was $\mathrm{Ca}^{2+}$-dependent and was inhibited by pretreating PMNs with saturating concentrations of $\mathrm{mPS}$ in solution (not shown) and by an $\mathrm{F}\left(\mathrm{ab}^{\prime}\right)_{2}$ fragment of the blocking anti-P-selectin $\mathrm{mAb}, \mathrm{G1}$, but not by the nonblocking mAb, S12 (Fig. 8). These features are 

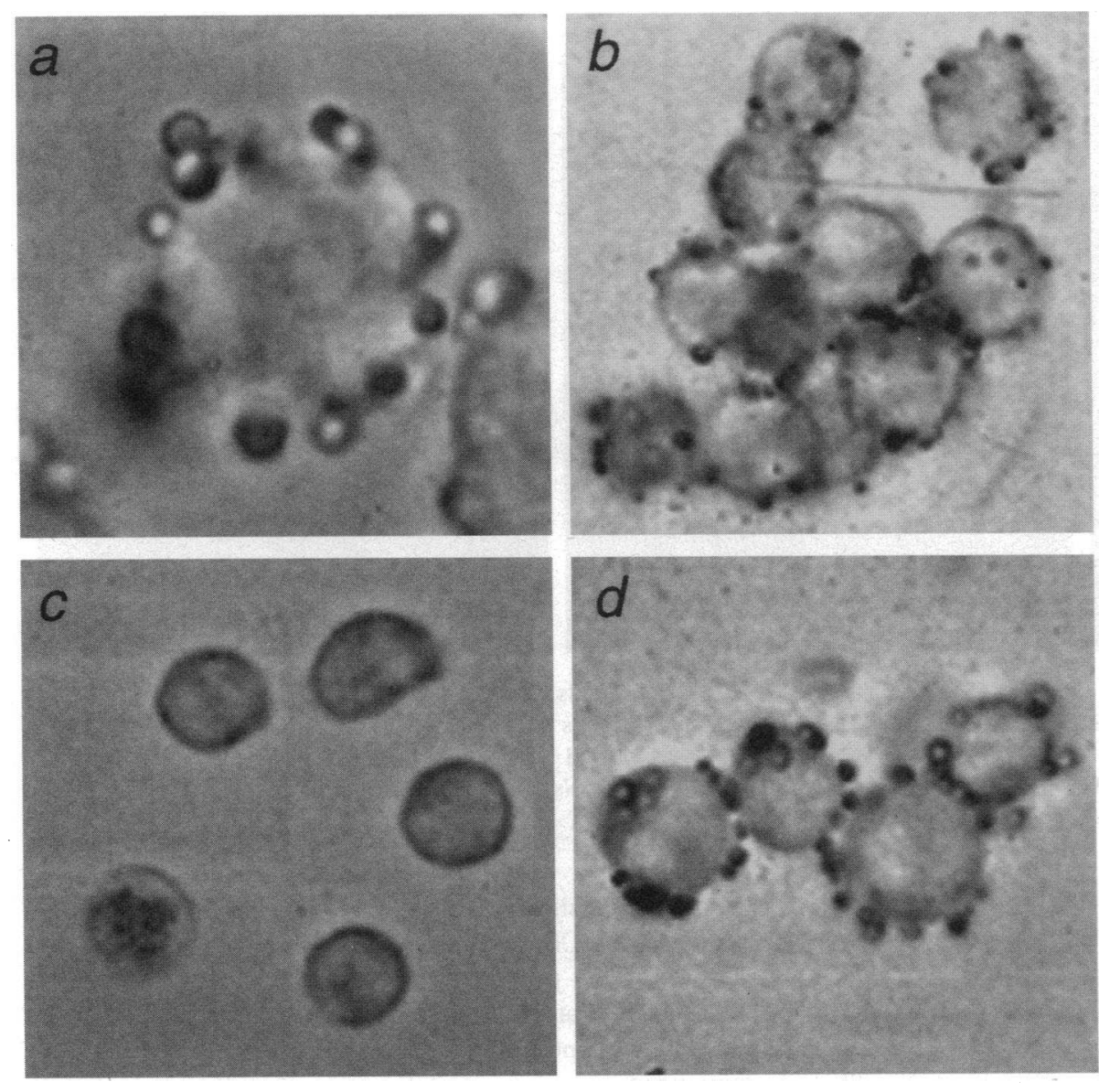

Figure 8. Latex beads coated with P-selectin bind specifically to unactivated PMNs. Latex beads were coated with P-selectin and an aliquot of beads was incubated with buffer alone or with the $F\left(a b^{\prime}\right)_{2}$ fragment of the blocking anti-P-selectin mAb, G1, or the $F\left(a b^{\prime}\right)_{2}$ fragment of the nonblocking $\mathrm{mAb}, \mathrm{S} 12(50 \mu \mathrm{g} / \mathrm{ml}$ for each $\mathrm{mAb})$. PMNs at $5.5 \times 10^{6}$ cells $/ \mathrm{ml}$ in HBSS $/ \mathrm{A}$ were incubated with P-selectin-coated beads and then fixed in glutaraldehyde. They were then examined by light microscopy and photographed. ( $a$ and $b$ ) PMNs incubated with P-selectin-coated beads in the absence of antibody; (c) PMNs incubated with P-selectin-coated beads treated with a blocking $\mathrm{mAb}$ against P-selectin, G1, (d) PMNs incubated with P-selectincoated beads treated with the nonblocking mAb, S12. Magnification: (a) 400; $(b-d)$ 198. characteristic of the interaction of P-selectin with its high affinity ligand(s) on PMNs $(15,22,36,43,54 a)$. To further characterize the binding sites for P-selectin-coated beads we incubated PMNs with a blocking monoclonal antibody, PL1, raised against the specific glycoprotein ligand, PSGL-1 (30). PL1 completely inhibited binding of P-selectin-coated microspheres (Fig. 9), suggesting that PSGL-1 accounts for all of the binding sites identified by this assay. In contrast PL2, a nonblocking $\mathrm{mAb}$ against PSGL-1, did not inhibit binding of the beads (Fig. 9).

We then examined the distribution of binding sites for Pselectin-coated beads on resting and activated PMNs. Inspection of many cells in multiple experiments demonstrated that the binding sites were randomly distributed over the surfaces of unactivated PMNs, although there were areas devoid of beads, and areas with patches of beads, on individual rounded, unstimulated PMNs (Fig. 8, $a, b$, and $d$; Fig. $9 a$; Fig. 10, $a$ and $b$ ). There was some aggregation of the P-selectin-coated beads before addition to the PMN suspension, potentially accounting for patches of beads on the cell surfaces, although the beads remained monodispersed for the most part. It was necessary to adjust the focal plane of the microscope to fully appreciate the random distribution of beads over the global surface of the PMNs. Frequently, the microspheres adhered to more than one PMN, causing them to form clusters of two to four cells (Figs. $8 d$ and $10 b$ ) and occasional large clusters (Fig. $8 b$ ). This was not seen when control beads coated with albumin alone were used, or when binding of P-selectin-coated beads to PMN ligands was blocked by removal of $\mathrm{Ca}^{2+}$ or by mAb G1 (Fig. $8 c$ ).

In contrast to the appearance of resting cells, many activated PMNs were polarized and the beads coated with P-selectin were dramatically clustered on the uropods (Fig. $10 c$ ). Few beads were seen on other areas of the cell surface when the focal plane of the microscope was adjusted for global inspection. When individual PMNs that had not been fixed were viewed continuously after addition of PAF, movement of P-selectincoated beads from the dispersed distribution (Fig. 8, $a$ and $b$; Fig. 10, $a$ and $b$ ) to the localized pattern (Fig. $10 c$ ) occurred within minutes, similar to the kinetics of decreased adhesion to P-selectin shown in Figs. 1 and 2 . We noted an equivalent redistribution of beads coated with P-selectin to the uropod whether PMNs were stimulated with PAF or $\mathrm{ALP}$, and when sequential stimulation was used to cause pronounced formation of uropods (41). We asked if binding of P-selectin-coated beads to ligands clustered on the uropods of activated PMNs was specific, as it was with ligands diffusely distributed on the surfaces of unactivated cells (Fig. 8). As with resting PMNs, binding of beads coated with P-selectin to activated PMNs was completely inhibited by the $\mathrm{F}\left(\mathrm{ab}^{\prime}\right)_{2}$ fragment of the blocking anti-P-selectin mAb, G1 (Fig. $10 d$ ), but not by the nonblocking $\mathrm{mAb}, \mathrm{S} 12$ (Fig. $10 e$ ). We then determined the effect of cytochalasin D on the distribution of beads coated with Pselectin, since this prevents the activation-dependent decreased adhesion to P-selectin presented by transfected cells (Figs. 4 and $6 b$ ). Pretreatment with cytochalasin D before activation 

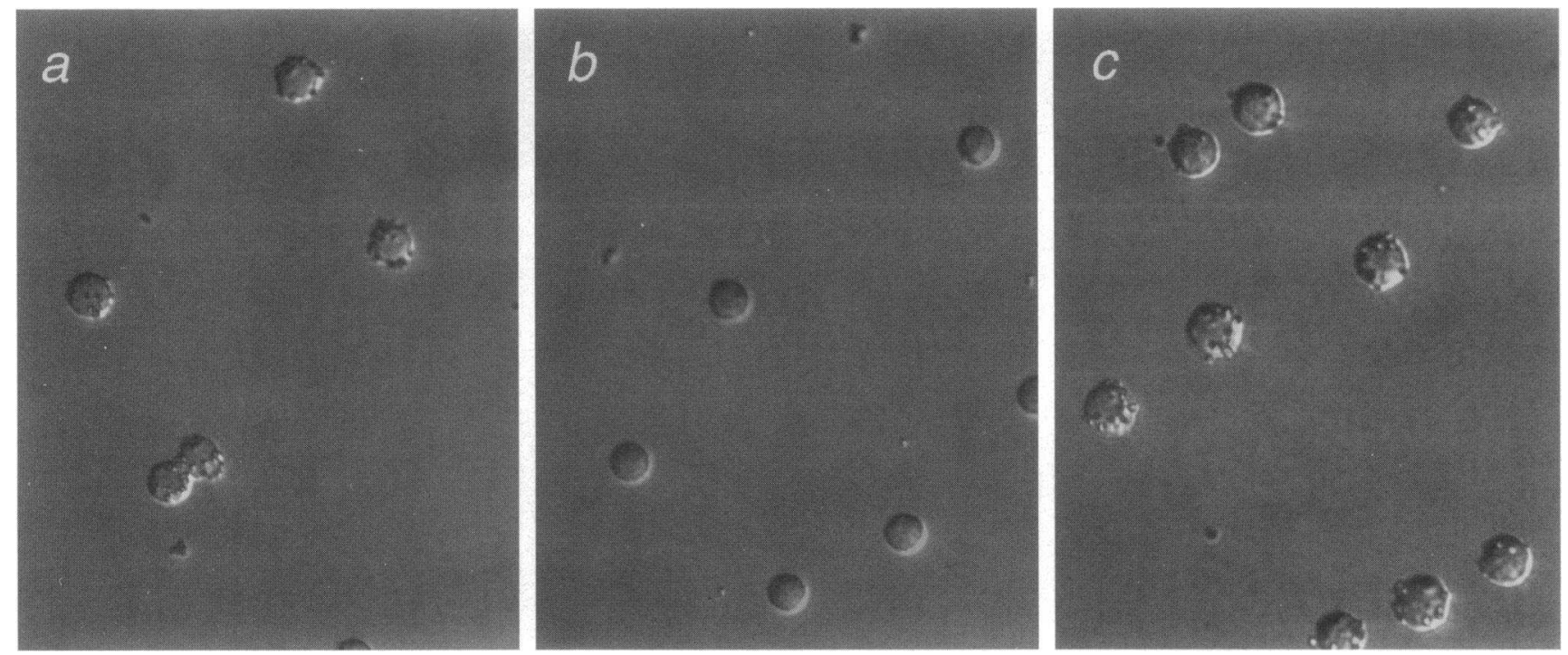

Figure 9. An antibody against PSGL-1 blocks binding of P-selectin-coated beads to neutrophils. PMNs were pretreated with buffer, with PL1, a blocking mAb to PSGL-1, or with a nonblocking mAb, PL2, as described in Methods. The cells were then incubated with P-selectin-coated latex beads for $15 \mathrm{~min}$ and fixed in glutaraldehyde. The association of beads with PMNs was viewed with Normarski interference contrast optics and photographed at $\times 156$. (a) Buffer-treated PMNs, $(b)$ PMNs pretreated with PL1, and (c) PMNs pretreated with PL2.

prevented both the change in shape and the redistribution of the beads on the PMN surface (Fig. $10 f$ ). This indicates that the topography of ligands for P-selectin on PMNs is regulated by cytoskeletal interactions. Furthermore, activation-dependent alterations in ligand distribution may be associated with decreased tightness of adhesion of PMNs to P-selectin at cell surfaces (Figs. 1-4).

\section{Discussion}

Adhesion molecules that tether PMNs to endothelial cells must be dynamically altered during regulated targeting of the leukocytes to inflammatory sites $(1,4,5,18,19,49)$. On stimulated endothelial cells, selectins and members of the immunoglobulin-like family of tethering molecules are transiently expressed, each with different kinetics (reviewed in references 1 and 3 ). The adhesive phenotype of the PMN is also dynamically modified. Both the function and the number of CD11/CD18 integrins are upregulated $(17,18)$. The functional up-regulation is transient $(18,33,55,56)$ and the PMNs return to the basal state of adhesiveness unless continuously or repetitively stimulated (41). Adhesion mediated by L-selectin on leukocytes is also transient: L-selectin is first activated (57) and then shed (52). Here we describe a dynamic feature of tethering of PMNs that has not been recognized before: reduced tightness of adhesion of PMNs to P-selectin, which results from cellular activation and is associated with redistribution of ligands for P-selectin on the PMN surface. The kinetics of the reduced adhesion of activated PMNs to P-selectin (Fig. 1) allow the modification to occur as the CD11/CD18 integrins become maximally engaged $(33,55,56)$. Also, the reduced adhesion of activated PMNs to surface P-selectin requires blockade of the CD11/ CD18 integrins for full detection (Fig. 3 ). These features suggest that, in vivo, a transition may occur from exclusive tethering by P-selectin early in the adhesive interaction, through a stage in which P-selectin and CD11/CD18 integrins act cooper- atively to establish tight adhesion $(8,15)$, to adhesion dominated by CD11/CD18 integrins. Bond trading in this fashion would potentially provide a mechanism for precise regulation of adhesion so that irreversible sticking is prevented but, at the same time, susceptibility of the PMN to dislodgment by flow is minimized.

Binding of P-selectin to its ligands on the PMN is reversible without cellular activation during a rolling interaction in which it is the only tethering mechanism involved; this may be because of rapid on-off rates of association between P-selectin and the ligands (8). Therefore cellular activation is not required to disengage from P-selectin. However, this may not apply at later times as the cell becomes stationary. Active modification of bonds with P-selectin may be required after the CD11/CD18 integrins establish tight adhesion and cellular spreading has occurred, causing multiple binding sites to be engaged $(8,15$, 22 ). Active modification may also be important if P-selectin is expressed at high local site density, or if shear forces are very low (5). Once established by an arrested cell, the CD11/CD18 integrin bonds are resistant to shear (8) and can maintain adhesion if tethering mediated by P-selectin is reduced. Complete reversal of the P-selectin bond may not be necessary; partial loosening of the bond resulting from cellular activation may be sufficient to allow motile leukocytes to release from P-selectin as they exert tractive forces. The time course of loosening of the bonds between P-selectin and its ligands on activated PMNs (Fig. 1) suggests that this may occur as the surface density of P-selectin on the endothelial cell is reduced by reinternalization $(1,2)$, which may also contribute to release of the leukocytes. Ultimately, the $\beta_{2}$ integrin bonds are also down-modulated (18, $33,54,56$ ), presumably through alterations in the cytoplasmic domains of the $\alpha$ and $\beta$ chains. There is evidence that events of this sort occur at the endothelial surface. When PMNs are incubated with endothelial cells that are stimulated to coexpress P-selectin and PAF the leukocytes adhere and detach (33), indicating that bonds involving P-selectin and CD11/CD18 in- 

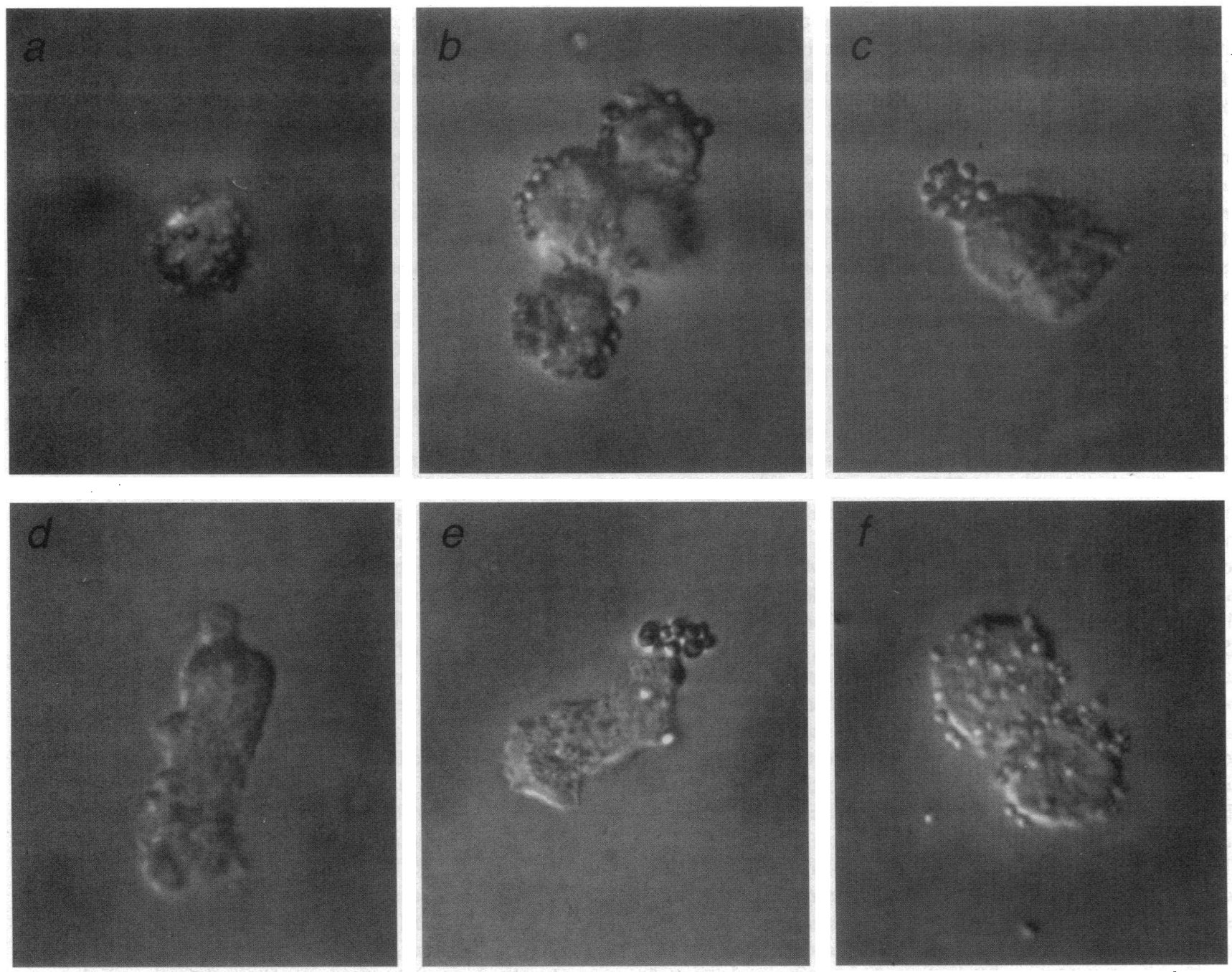

Figure 10. Binding sites for P-selectin-coated beads are redistributed to the uropods of activated PMNs. Latex beads were coated with P-selectin and an aliquot of beads were incubated with buffer alone or with either $50 \mu \mathrm{g} / \mathrm{ml}$ of the $\mathrm{F}\left(\mathrm{ab}^{\prime}\right)_{2}$ fragment of the blocking anti-P-selectin mAb, $\mathrm{G} 1$, or the $\mathrm{F}\left(\mathrm{ab}^{\prime}\right)_{2}$ fragment of the nonblocking mAb, S12: PMNs were sequentially treated with $10^{-10} \mathrm{M} \mathrm{fMLP}$ for 5 min followed by $5 \times 10^{-9}$ M f MLP for $10 \mathrm{~min}(41)$. Some PMNs were pretreated with cytochalasin $\mathrm{D}\left(2 \times 10^{-6} \mathrm{M}\right)$ for $10 \mathrm{~min}$ at $37^{\circ} \mathrm{C}$. The cytochalasin $\mathrm{D}$ was also present at $2 \times 10^{-6} \mathrm{M}$ during the second $\mathrm{f}$ MLP stimulus. PMNs and beads were incubated together for 15 min and then fixed in gluteraldehyde. The cells were viewed with Normarski interference contrast optics and photographed at $\times 250(a$ and $b)$ or $\times 400(c-f)$. The conditions were: resting PMNs incubated with P-selectin-coated beads in the absence of cytochalasin D or antibody $(a$ and $b)$; activated PMNs incubated with Pselectin-coated beads in absence of cytochalasin D or antibody $(c)$; activated PMNs incubated with P-selectin-coated beads pretreated with mAb G1 (d); activated PMNs incubated with P-selectin-coated beads pretreated with mAb S12 (e); activated PMNs pretreated with cytochalasin D and incubated with P-selectin-coated beads in the absence of antibody $(f)$.

tegrins (15) have been established and then broken. The time course of adhesion and release (33) is consistent with the sequence of bond modification suggested above, and with the timing of transmigration in vivo $(5,19$, and cited references $)$.

Rolling of PMNs on P-selectin in model membranes is reduced by treatment of the leukocytes with PMA (8). In addition, rolling of PMNs on immobilized platelets expressing P-selectin is reduced by prior stimulation of the PMNs with $\mathrm{fMLP}$ (58), and P-selectin-dependent adhesion of platelets to neutrophils is reduced by activation of the leukocytes (59). These studies are consistent with our observations of activation-dependent decreased adhesion of PMNs to P-selectin at cell surfaces. A mechanism proposed for decreased adhesion of activated PMNs to P-selectin is alteration of their shape, making them more susceptible to shear-induced dislodgement in a flowing system
(8). However, we found that activation of PMNs reduced the tightness of adhesion to P-selectin in static assays (Figs. 1 and 2 ), as well as under conditions of shear (Fig. 3). This indicated that increased susceptibility of activated PMNs to tumbling and dislodgement by flow could not be the exclusive mechanism. Shedding of L-selectin was proposed as a second explanation for decreased attachment to P-selectin (58). However, we observed that cytochalasin D treatment of PMNs prevented the decreased adhesion to P-selectin, but not shedding of L-selectin (Fig. 6). These experiments indicate that release of L-selectin is not the mechanism for decreased adhesion of activated PMNs to surface P-selectin.

After excluding shedding of L-selectin, we explored other potential mechanisms for decreased adhesion of activated PMNs to P-selectin. Proteases and sialidases are expressed and released 
when PMNs are activated (60), suggesting the possibility of enzymatic degradation of ligands for P-selectin. Alternatively, ligands could be internalized. However, our assays using flow cytometry indicated no decrease in the number of binding sites for P-selectin on PMNs stimulated with PAF or fMLP (Fig. 7 and data not shown). Also, we previously reported no difference in the apparent number of binding sites for radiolabeled Pselectin on PMNs activated with PMA compared to unactivated PMNs (36). While it is possible that more precise measurements of the number of high affinity binding sites for P-selectin using antibodies to these ligands or other techniques will give a different answer, these results indicate that quantitative downregulation of these structures is not an exclusive mechanism for activation-dependent decreased adhesion of PMNs to P-selectin (Figs. 1-4).

Changes in the binding efficiency of the ligands for P-selectin, or their redistribution, are alternative mechanisms for reduced adhesion of activated PMNs. Our finding that pretreatment of PMNs with cytochalasin D before activation prevented their decreased binding to transfected CHO cells (Fig. 4) is consistent with either mechanism because cytochalasins regulate the activity of certain adhesion molecules (61) and also alter the topography of adhesion molecules on the cell surface (54). To begin to explore these possibilities, we examined ligands on resting and activated PMNs using beads coated with P-selectin. These microspheres bound specifically to the plasma membranes of PMNs (Figs. 8 and 9). The pattern of adherent beads indicated that the ligands for P-selectin are randomly distributed over the surfaces of rounded, unactivated leukocytes (Figs. 8-10). In contrast, we found dramatic redistribution of binding sites for P-selectin-coated beads on activated PMNs. The microspheres were predominantly clustered at one end of polarized leukocytes (Fig. $10 \mathrm{c}$ ). The appearance of the cells indicates that this area is the uropod, the posterior structure that develops when PMNs are induced to undergo shape change (41, 54). Thus, redistribution of ligands on the plasma membranes of activated PMNs (Fig. $10 c$ ), mediated by cytoskeletal interactions (Figs. 4 and $10 f$ ), is associated with reduced adhesion to P-selectin at cell surfaces (Figs. 1-4). The concordance of the two events suggests that redistribution of ligands may be one mechanism of decreased adhesiveness. Redistribution of other surface molecules, including CD11b/CD18, to the uropod also occurs in activated, polarized PMNs $(41,54,62,63)$. Localization of CD11b/CD18 at the uropod, detected by binding of albumin-coated beads, was associated with release from protein-coated surfaces $(41,54)$, and impaired redistribution of adhesive ligands was suggested as a mechanism of impaired migration of neonatal neutrophils (64). How redistribution of binding sites to the uropod contributes to release of leukocytes from surface adhesion is not clear. It was proposed that the affinity of certain adhesive ligands at the anterior lamellipodium of a migrating neutrophil may be greater than at the cell body or the uropod or, alternatively, that the ruffled surface of the lamellipodium may allow for binding to multiple counterligands on opposing cells, potentially increasing the avidity of the interaction (65). Broad lamellipodial regions of migrating neurons require greater detachment force than do filopodial regions, which resemble the uropods of PMNs, apparently because of the smaller surface area of the filopodial regions and a consequently smaller number of attachment sites (66). However, the significance of redistribution of $\mathrm{CD} 11 \mathrm{~b} / \mathrm{CD} 18$ and of ligands for $\mathrm{P}$ selectin to the uropods of activated PMNs, and of the association of these events with reduced surface adhesion, remains to be clarified. Also, we do not yet know if redistribution of P-selectin ligands occurs on adherent PMNs, as it does on PMNs activated in suspension (Fig. 10).

Myeloid leukocytes may bear more than one ligand for Pselectin $(67,68)$. However, PL1, a blocking antibody against PSGL-1 (30), completely inhibited binding of P-selectincoated beads to PMNs in our experiments (Fig. 9), indicating that PSGL-1 is the critical ligand in this assay. PSGL-1 has been rigorously characterized $(30,44,54 a, 68,69)$ and must engage for PMNs to roll on cells expressing P-selectin at physiologic shear forces (30). The distribution of beads on resting PMNs suggests that PSGL-1 is equally available for interaction with P-selectin during rolling interactions regardless of which part of the PMN contacts the endothelium first (Figs. 8-10), consistent with this function. Also, PSGL-1 is located on the tips of microvilli on resting PMNs (30), making it accessible for immediate interactions. Altered distribution induced by cellular activation (Fig. 10) provides a potential mechanism for dynamic regulation. Ultrastructural studies are required to define more precisely how activation of PMNs affects the distribution of PSGL-1 on the cell surface.

If the PMNs are first activated with PAF or $\mathrm{ALP}$ in solution, their ability to adhere to P-selectin at cell surfaces is rapidly reduced (Table I). Previously, it was reported that activation of PMNs with IL-8 reduces their adhesion to endothelial cells that are stimulated with IL-1, TNF $\alpha$, or LPS, and that IL-8 acts as a leukocyte adhesion inhibitor (LAI) $(70,71)$. Several features of the LAI effect of IL-8 are similar to those of the activation-dependent decreased binding to P-selectin that we describe here, including prevention by cytochalasins (72). A difference is that PAF and $\mathrm{LTB}_{4}$ were reported not to have LAI activity in assays of PMN adhesion to endothelial cells stimulated with IL-1 (71). The differential effects of IL-8 and certain other agonists, compared to PAF and $\mathrm{LTB}_{4}$, was proposed to be due to more prolonged reorganization of the actin cytoskeleton by IL-8 (72). In contrast, we found that both of the lipid mediators induce decreased adhesion of PMNs to Pselectin, as did IL-8 (Table I). Human endothelial cells express E-selectin, rather than P-selectin, when stimulated with IL-1 and other cytokines (42, Lorant, D. E., R. P. McEver, T. M. McIntyre, S. M. Prescott and G. A. Zimmerman, unpublished observations), the conditions used in experiments to examine the LAI properties of IL-8 $(71,72)$. This suggests that activation of PMNs with IL-8 may modify ligands for E-selectin on their surfaces, reducing the avidity of their binding or altering their distribution in a fashion equivalent to that we report here for P-selectin ligands. If so, PAF, $\mathrm{LTB}_{4}$ and IL-8 may induce separate activation pathways that differentially modify specific binding sites for P-selectin and E-selectin. However, experiments examining the effect of activation of PMNs by these agonists on adhesion to E-selectin expressed by heterologous cells, or in purified form, have not been reported.

Because treatment of PMNs with activating signals before interaction with cells expressing P-selectin impairs adhesion (Table I, Fig. 2), activation of PMNs in the blood before initial tethering may impair their targeting to sites of tissue infection or injury by reducing their ability to bind to P-selectin expressed by locally stimulated endothelial cells. Activation of PMNs by agonists presented in solution may also inhibit neutrophil targeting in vivo: injection of IL-8 into the blood of experimental animals reduces PMN accumulation at extravascular sites (73, 
74). These findings suggest that the regulated sequence of tethering, bond modification, and bond breaking required for targeting and transmigration of PMNs is most favorably accomplished when activation occurs by juxtacrine stimulation of PMNs at the endothelial surface (reviewed in reference 25). PAF can clearly act in this fashion $(15,21,22)$ and IL-8 may also activate PMNs when localized at endothelial surfaces (4, 75 ). Activation of PMNs by IL-8 in a spatially localized fashion after they have been initially tethered, rather than in the flowing blood before initial tethering, may explain how IL-8 facilitates transmigration when locally expressed $(23,24)$ instead of inhibiting PMN targeting as it does when injected intravascularly $(73,74)$. Localization of signaling molecules, such as PAF and IL-8, may be a key mechanism for regulated modification of bonds between endothelial cells and PMNs, and generalized release of these signals into the blood may be a mechanism of dysregulated inflammation in disease.

\section{Acknowledgments}

The authors thank Donelle Benson, Debi Dykstra, Wenhua Li, and Margaret Vogel for excellent technical assistance, Michelle Bills for preparation of the manuscript, and the staff of the LDS Hospital Labor and Delivery Service for invaluable help in collecting umbilical samples. We also thank Magali Disdier for the contribution of transfected cells, Patrick Beatty, John Bohnsack, Kathy Cabrian, and T.K. Kishimoto for the gifts of antibodies, John Fenton for the gift of purified thrombin, and Andrew Weyrich, Kamala Patel, Bonnie Hughes, and Kurt Albertine for helpful discussions. Diana Lim prepared the photographs.

This work was supported by the Nora Eccles Treadwell Foundation, grants from the National Institutes of Health (NIH) (HL-44525, HL07636, HL-34363, HL-45510), a Physician Scientist Award (HL02726) from the NIH (D.E. Lorant), a Rocky Mountain Center for the Biology of Development Award from the NIH (5 P30 HD 27827) (D.E. Lorant), and a clinician Scientist Award from the American Heart Association (K.L. Moore).

\section{References}

1. Zimmerman, G. A., S. M. Prescott, and T. M. McIntyre. 1992. Endothelial cell interactions with granulocytes: tethering and signaling molecules. Immunol Today. 13:93-100.

2. McEver, R. P. 1992. Leukocyte-endothelial cell interactions. Curr. Opin. Cell Biol. 4:840-849.

3. Bevilacqua, M. P. 1993. Endothelial-leukocyte adhesion molecules. Annu. Rev. Immunol. 11:767-804.

4. Adams, D. H., and S. Shaw. 1994. Leukocyte-endothelial interactions and regulation of leukocyte migration. Lancet. 343:831-836.

5. Granger, D. N., and P. Kubes. 1994. The microcirculation and inflammation: modulation of leukocyte-endothelial cell adhesion. J. Leukocyte Biol. 55:662675.

6. Lasky, L. A. 1993. A "roll" in acute inflammation. Curr. Biol. 3:680682.

7. Abbassi, O., T. K. Kishimoto, L. V. McIntire, D. C. Anderson, and C. W. Smith. 1993. E-selectin supports neutrophil rolling in vitro under conditions of flow. J. Clin. Invest. 92:2719-2730.

8. Lawrence, M. B., and T. A. Springer. 1991. Leukocytes roll on selectin at physiologic flow rates: distinction from and prerequisite for adhesion through integrins. Cell. 65:859-873.

9. Lawrence, M. B., and T. A. Springer. 1993. Neutrophils roll on E-selectin. I. Immunol. 151:6338-6346.

10. Mayadas, T. N., R. C. Johnson, H. Rayburn, R. O. Hynes, and D. D. Wagner. 1993. Leukocyte rolling and extravasation are severely compromised in P-selectin-deficient mice. Cell. 74:541-554.

11. Ley, K., T. F. Tedder, and G. S. Kansas. 1993. L-selectin can mediate leukocyte rolling in untreated mesenteric venules in vivo independent of $\mathrm{E}$ - or $\mathrm{P}$ selectin. Blood. 82:1632-1638.

12. von Andrian, U. H., J. D. Chambers, E. L. Berg, S. A. Michie, D. A Brown, D. Karolak, L. Ramezani, E. M. Berger, K.-E. Arfors, and E. C. Butcher.
1993. L-selectin mediates neutrophil rolling in inflamed venules through sialyl lewis ${ }^{x}$-dependent and -independent recognition pathways. Blood. 82:182-191.

12a. Jones, D. A., O. Abbassi, L. V. McIntire, R. P. McEver, and C. W. Smith. 1993. P-selectin mediates neutrophil rolling on histamine-stimulated endothelial cells. Biophys. J. 65:1560-1569.

13. Kishimoto, T. K., and D. C. Anderson. 1992. The role of integrins in inflammation. In Inflammation: Basic Principles and Clinical Correlates. 2nd ed. J. I. Gallin, I. M. Goldstein, and R. Snyderman, editors. Raven Press, Ltd., New York. 353-406.

14. Ley, K., P. Gaehtgens, C. Fennie, M. S. Singer, L. A. Lasky, and S. D. Rosen. 1991. Lectin-like cell adhesion molecule 1 mediates leukocyte rolling in mesenteric venules in vivo. Blood. 77:2553-2555.

15. Lorant, D. E., K. D. Patel, T. M. McIntyre, R. P. McEver, S. M. Prescott, and G. A. Zimmerman. 1991. Coexpression of GMP-140 and PAF by endothelium stimulated by histamine or thrombin: a juxtacrine system for adhesion and activation of neutrophils. J. Cell. Biol. 115:223-234.

16. von Andrian, U. H., J. D. Chambers, L. M. McEvoy, R. F. Bargatze K.-E. Arfors, and E. C. Butcher. 1991. Two step model of leukocyte-endothelia cell interaction in inflammation: distinct roles for LECAM-1 and the leukocyte $\beta_{2}$ integrins in vivo. Proc. Natl. Acad. Sci. USA. 88:7538-7542.

17. Hynes, R. O. 1992. Integrins: versatility, modulation, and signaling in cell adhesion. Cell. 69:11-25.

18. Diamond, M. S., and T. A. Springer. 1994. The dynamic regulation of integrin adhesiveness. Curr. Biol. 4:506-517.

19. Movat, H. Z. 1985. Cellular emigration. In The Inflammatory Reaction. Elsevier Science Ltd., Amsterdam, New York, Oxford. 161-197.

20. Prescott, S. M., G. A. Zimmerman, and T. M. McIntyre. 1984. Human endothelial cells in culture produce platelet-activating factor (1-alkyl-2-acetyl-snglycero-3-phosphocholine) when stimulated with thrombin. Proc. Natl. Acad. Sci. USA. 81:3534-3538.

21. Zimmerman, G. A., T. M. McIntyre, M. Mehra, and S. M. Prescott. 1990. Endothelial cell-associated platelet-activating factor: a novel mechanism for signaling intercellular adhesion. J. Cell Biol. 110:529-540.

22. Lorant, D. E., M. K. Topham, R. E. Whatley, R. P. McEver, T. M McIntyre, S. M. Prescott, and G. A. Zimmerman. 1993. Inflammatory roles of Pselectin. J. Clin. Invest. 92:559-570.

23. Huber, A. R., S. L. Kunkel, R. F. Todd, and S. J. Weiss. 1991. Regulation of transendothelial migration by endogenous interleukin-8. Science (Wash. DC). 254:99-102.

24. Kuijpers, T. W., B. C. Hakkert, M. H. L. Hart, and D. Roos. 1992 Neutrophil migration across monolayers of cytokine-prestimulated endothelial cells: a role for platelet-activating factor and IL-8. J. Cell Biol. 117:564-572.

25. Zimmerman, G. A., D. E. Lorant, T. M. McIntyre, and S. M. Prescott. 1993. Juxtacrine intercellular signaling: another way to do it. Am. J. Respir. Cell Mol. Biol. 9:573-577.

26. Muller, W. A., S. A. Weigl, X. Deng, and D. M. Phillips. 1993. PECAM1 is required for transendothelial migration of leukocytes. J. Exp. Med. 178:449460.

27. Johnston, G. I., A. Kurosky, and R. P. McEver. 1989. Structural and biosynthetic studies of the granule membrane protein, GMP-140, from human platelets and endothelial cells. J. Biol. Chem. 264:1816-1823.

28. Geng, J.-G., M. P. Bevilacqua, K. L. Moore, T. M. McIntyre, S. M. Prescott, J. M. Kim, G. A. Bliss, G. A. Zimmerman, and R. P. McEver. 1990 Rapid neutrophil adhesion to activated endothelium mediated by GMP-140. Nature (Lond.). 343:757-760.

29. Maruyama, S., H. Kubagawa, and M. D. Cooper. 1985. Activation of human $B$ cells and inhibition of their terminal differentiation by monoclonal anti$\mu$ antibodies. J. Immunol. 135:192-199.

30. Moore, K. L., K. P. Patel, R. E. Breuhl, L. Fugang, D. A. Johnson, H. S. Lichenstein, R. D. Cummings, D. F. Bainton, and R. P. McEver. 1995. P-selectin glycoprotein ligand mediates rolling of human neutrophils on P-selectin. J. Cell Biol. 128:661-671.

31. Beatty, P. G., J. A. Leddetter, P. J. Martin, T. H. Price, and J. A. Hansen. 1983. Definition of a common leukocyte cell-surface antigen (Lp 95-150) associated with diverse cell-mediated immune functions. J. Immunol. 131:2913-2918.

32. Kishimoto, T. K., M. A. Jutila, and E. C. Butcher. 1990. Identification of human peripheral lymph node homing receptor: a rapidly down-regulated adhesion molecule. Proc. Natl. Acad. Sci. USA. 87:2244-2248.

33. Zimmerman, G. A., T. M. McIntyre, and S. M. Prescott. 1985. Thrombin stimulates the adherence of neutrophils to human endothelial cells in vitro. $J$. Clin. Invest. 76:2235-2246.

34. Disdier, M., J. H. Morrissey, R. D. Fugate, D. F. Bainton, and R. P. McEver. 1992. Cytoplasmic domain of P-selectin (CD62) contains the signal for sorting into the regulated secretory pathway. Mol. Biol. Cell. 3:309-321.

35. Bohnsack, J. F., S. K. Akiyama, C. H. Damsky, W. A. Knape, and G. A. Zimmerman. 1990. Human neutrophil adherence to laminin in vitro: evidence for a distinct neutrophil integrin receptor for laminin. J. Exp. Med. 171:1221-1237.

36. Moore, K. L., A. Varki, and R. P. McEver. 1991. GMP-140 binds to a glycoprotein receptor on human neutrophils: evidence for a lectin-like interaction. J. Cell Biol. 112:491-499. 
37. Spertini, O., F. W. Luscinskas, G. S. Kansas, J. M. Munro, J. D. Griffin, M. A. Gimbrone, Jr., and T. F. Tedder. 1991. Leukocyte adhesion molecule-1 (LAM-1, L-selectin) interacts with an inducible endothelial cell ligand to support leukocyte adhesion. J. Immunol. 147:2565-2573.

37a. Ley, K., E. Lundgren, E. Berger, and K.-E. Arfors. 1989. Shear-dependent inhibition of granulocyte adhesion to cultured endothelium by dextran sulfate. Blood. 73:1324-1330.

38. Dobrina, A., T. M. Carlos, B. R. Schwartz, P. G. Beatty, H. D. Ochs, and J. M. Harlan. 1990. Phorbol ester causes down-regulation of CD11/CD18independent neutrophil adherence to endothelium. Immunology. 69:429-434.

39. Dransfield, I., C. Cabañas, A. Craig, and N. Hogg. 1992. Divalent cation regulation of the function of the leukocyte integrin LFA-1. J. Cell Biol. 116:219226.

40. Ushiyama, S., T. M. Laue, K. L. Moore, H. P. Erickson, and R. P. McEver. 1993. Structural and functional characterization of monomeric soluble P-selectin and comparison with membrane P-selectin. J. Biol. Chem. 268:15229-15237.

41. Hughes, B. J., J. C. Hollers, E. Crockett-Torabi, and C. W. Smith. 1992 Recruitment of CD11b/CD18 to the neutrophil surface and adherence-dependent cell locomotion. J. Clin. Invest. 90:1687-1696.

42. Patel, K. D., D. E. Lorant, D. A. Jones, S. M. Prescott, T. M. McIntyre, and G. A. Zimmerman. 1993. Juxtacrine interactions of endothelial cells with leukocytes: tethering and signaling molecules. Behring Inst. Mitt. 92:144-164.

43. Moore, K. L., N. L. Stults, S. Diaz, D. F. Smith, R. D. Cummings, A. Varki, and R. P. McEver. 1992. Identification of a specific glycoprotein ligand for P-selectin (CD62) on myeloid cells. J. Cell Biol. 118:445-456.

44. Sako, D., X.-J. Chang, K. M. Barone, G. Vachino, H. M. White, G. Shaw, G. M. Veldman, K. M. Bean, T. J. Ahern, B. Furie, et al. 1993. Expression cloning of a functional glycoprotein ligand for P-selectin. Cell. 75:1179-1186.

45. Ye, R. D., E. R. Prossnitz, A. Zou, and C. G. Cochrane. 1991. Characterization of a human cDNA that encodes a functional receptor for platelet activating factor. Biochem. Biophys. Res. Commun. 180:105-111.

46. Cooper, J. A. 1987. Effects of cytochalasin and phalloidin on actin. J. Cell Biol. 105:1473-1478.

47. Howard, T. H., J. Casella, and S. Lin. 1981. Correlation of the biologic effects and binding of cytochalasins to human polymorphonuclear leukocytes. Blood. 57:399-405.

48. Marks, P. W., B. Hendey, and F. R. Maxfield. 1991. Attachment to fibronectin or vitronectin makes human neutrophil migration sensitive to alterations in cytosolic free calcium concentration. J. Cell Biol. 112:149-158.

49. Maxfield, F. R. 1993. Regulation of leukocyte locomotion by $\mathrm{Ca}^{2+}$. Trends Cell Biol. 3:386-391.

50. Sha'afi, R. I., R. Y. Shefcyk, T. F. P. Molski, M. Volpi, P. H. Naccache, J. R. White, M. B. Feinstein, and E. L. Becker. 1986. Is a rise in intracellular concentration of free calcium necessary or sufficient for stimulated cytoskeletalassociated actin? J. Cell Biol. 102:1459-1463.

51. Griffin, J. D., O. Spertini, T. J. Ernst, M. P. Belvin, H. B. Levine, Y. Kanakura, and T. F. Tedder. 1990. Granulocyte-macrophage colony-stimulating factor and other cytokines regulate surface expression of the leukocyte adhesion molecule-1 on human neutrophils, monocytes, and their precursors. J. Immunol. 145:576-584.

52. Kahn, J., R. H. Ingraham, F. Shirley, G. I. Migaki, and T. K. Kishimoto. 1994. Membrane proximal cleavage of L-selectin: identification of the cleavage site and a 6-kD transmembrane peptide fragment of L-selectin. J. Cell Biol. $125: 461-470$

53. Picker, L. J., R. A. Warnock, A. R. Burns, C. M. Doerschuk, E. L. Berg, and E. C. Butcher. 1991. The neutrophil selectin LECAM-1 presents carbohydrate ligands to the vascular selectins ELAM-1 and GMP-140. Cell. 66:921-933.

54. Smith, C. W., and J. C. Hollers. 1980. Motility and adhesiveness in human neutrophils. Redistribution of chemotactic factor-induced adhesion sites. J. Clin. Invest. 65:804-812.

54a. Norgard, K. E., K. L. Moore, S. Diaz, N. L. Stults, S. Ushiyama, R. P. McEver, R. D. Cummings, and A. Varki. 1993. Characterization of a specific ligand for P-selectin on myeloid cells. J. Biol. Chem. 268:12764-12774.

55. Carveth, H. J., J. F. Bohnsack, T. M. McIntyre, M. Baggiolini, S. M.
Prescott, and G. A. Zimmerman. 1989. Neutrophil activating factor (NAF) induces polymorphonuclear leukocyte adherence to endothelial cells and to subendothelial matrix proteins. Biochem. Biophys. Res. Commun. 162:387-393.

56. Lo, S. K., P. A. Detmers, S. M. Levin, and S. D. Wright. 1989. Transient adhesion of neutrophils to endothelium. J. Exp. Med. 169:1779-1793.

57. Spertini, O., G. S. Kansas, J. M. Munro, J. D. Griffin, and T. F. Tedder 1991. Regulation of leukocyte migration by activation of the leukocyte adhesion molecule-1 (LAM-1) selectin. Nature (Lond.). 349:691-694.

58. Buttrum, S. M., R. Hatton, and G. B. Nash. 1993. Selectin-mediated rolling of neutrophils on immobilized platelets. Blood. 82:1165-1174.

59. Rinder, H. M., J. L. Tracey, C. S. Rinder, D. Leitenberg, and B. R. Smith 1994. Neutrophil but not monocyte activation inhibits P-selectin-mediated platelet adhesion. Thromb. Haemostasis. 71:750-756.

60. Cross, A. S., and D. G. Wright. 1991. Mobilization of sialidase from intracellular stores to the surface of human neutrophils and its role in stimulated adhesion responses of these cells. J. Clin. Invest. 88:2067-2076.

61. Elmer, G. S., and T. S. Edington. 1994. Microfilament reorganization is associated with functional activation of $\alpha_{\mathrm{M}} \beta_{2}$ on monocytic cells. J. Biol. Chem. 269:3159-3166

62. Francis, J. W., R. F. Todd III, L. A. Boxer, and H. R. Petty. 1989 Sequential expression of cell surface $\mathrm{C} 3 \mathrm{bi}$ receptors during neutrophil locomotion J. Cell Physiol. 140:519-523.

63. Davis, B. H., R. J. Walter, C. B. Pearson, E. L. Becker, and J. M. Oliver 1982. Membrane activity and topography of f-Met-Leu-Phe-treated polymorphonuclear leukocytes: acute and sustained responses to chemotactic peptide. Am. J. Pathol. 108:206-216.

64. Anderson, D. C., B. J. Hughes, and C. W. Smith. 1981. Abnormal mobility of neonatal polymorphonuclear leukocytes. Relationship to impaired redistribution of surface adhesion sites by chemotactic factor or colchicine. J. Clin. Invest. 68:863-874.

65. Pytowski, B., F. R. Maxfield, and J. Michl. 1990. Fc and C3bi receptors and the differentiation antigen $\mathrm{BH} 2-\mathrm{Ag}$ are randomly distributed in the plasma membrane of locomoting neutrophils. J. Cell Biol. 110:661-668.

66. Zheng, J., R. E. Buxbaum, and S. R. Heidemann. 1994. Measurements of growth cone adhesion to culture surfaces by micromanipulation. J. Cell Biol. 127:2049-2060.

67. Lenter, M., A. Levinovitz, S. Isenmann, and D. Vestweber. 1994. Monospecific and common glycoprotein ligands for E- and P-selectin on myeloid cells. J. Cell Biol. 125:471-481.

68. McEver, R. P. 1994. Selectins. Curr. Opin. Immunol. 6:75-84.

69. Moore, K. L., S. F. Eaton, D. E. Lyons, H. S. Lichenstein, R. D. Cummings, and R. P. McEver. 1994. The P-selectin glycoprotein ligand from human neutrophils displays sialylated, fucosylated, $O$-linked poly- $N$-acetyllactosamine. J. Biol. Chem. 269:23318-23327.

70. Gimbrone, M. A., Jr., M. S. Obin, A. F. Brock, E. A. Luis, P. E. Hass, C. A. Hébert, Y. K. Yip, D. W. Leung, D. G. Lowe, W. J. Kohr, et al. 1989. Endothelial interleukin-8: a novel inhibitor of leukocyte-endothelial interactions. Science (Wash. DC). 246:1601-1603.

71. Luscinskas, F. W., J.-M. Kiely, H. Ding, M. S. Obin, C. A. Hébert, J. B. Baker, and M. A. Gimbrone, Jr. 1992. In vitro inhibitory effect of IL-8 and other chemoattractants on neutrophil-endothelial adhesive interactions. J. Immunol. 149:2163-2171.

72. Westlin, W. F., J.-M. Kiely, and M. A. Gimbrone, Jr. 1992. Interleukin-8 induces changes in human neutrophil actin conformation and distribution: Relationship to inhibition of adhesion to cytokine-activated endothelium. J. Leukocyte Biol. 52:43-51

73. Hechtman, D. H., M. I. Cybulsky, H. J. Fuchs, J. B. Baker, and M. A. Gimbrone, Jr. 1991. Intravascular IL-8: inhibitor of polymorphonuclear leukocyte accumulation at sites of acute inflammation. J. Immunol. 147:883-892.

74. Ley, K., J. B. Baker, M. I. Cybulsky, M. A. Gimbrone, Jr., and F. W. Luscinskas. 1993. Intravenous interleukin-8 inhibits granulocyte emigration from rabbit mesenteric venules without altering L-selectin expression or leukocyte rolling. J. Immunol. 151:6347-6357.

75. Rot, A. 1992. Endothelial binding of NAP-1/IL-8: role in neutrophil emigration. Immunol. Today. 13:291-294. 